\title{
Optimal Passive Filter Design for Effective Utilization of Cables and Transformers under Non-sinusoidal Conditions
}

\author{
Shady H. E. Abdel Aleem, \\ Member, IEEE \\ 15th of May Higher \\ Institute of Engineering \\ Cairo, Egypt \\ engyshady@ieee.org
}

\author{
Murat E. Balci, \\ Member, IEEE \\ Balikesir University \\ Balikesir, Turkey \\ mbalci@balikesir.edu.tr
}

\author{
Ahmed F. Zobaa, \\ Senior Member, IEEE \\ School of Engineering and \\ Design, Brunel University, \\ UB8 3PH Uxbridge, U.K \\ azobaa@ieee.org
}

\author{
Selcuk Sakar, \\ Gediz University \\ Izmir, Turkey \\ selcuk.sakar@gediz.edu.tr
}

\begin{abstract}
Transformers and cables have overheating and reduced loading capabilities under non-sinusoidal conditions due to the fact that their losses increases with not only rms value but also frequency of the load current. In this paper, it is aimed to employ passive filters for the effective utilization of the cables and transformers in the non-sinusoidal power systems. To attain this goal, an optimal passive filter design approach is provided to maximize the power factor definition, which takes into account frequency-dependent losses of the power transmission and distribution equipment, for the harmonically polluted systems. Obtained simulation results shows that the proposed approach has a considerable advantage on the reduction of the total transmission losses and the transformer's loading capability under non-sinusoidal conditions when compared to the traditional optimal filter design approach, which aims to maximize classical power factor definition. On the other hand, for the simulated system cases, both approaches lead to almost the same current carrying capability value of the cables.
\end{abstract}

Index Terms-Cable ampacity, C-type filters, harmonic distortion, non-sinusoidal conditions, optimal design.

\section{INTRODUCTION}

$\mathrm{P}$ resent day's power systems invariably have nonlinear loads, which inject harmonics into the system and give rise to nonsinusoidal voltages and currents. Accordingly, in the literature, considerable interests have been focused on the adverse effects of the harmonics on the power distribution equipment such as cables [1]-[4] and transformers [5]-[9]. It is seen from these studies that due to the fact that the resistances of the cables and the transformer windings increase with the frequency, they have excessive losses even if the rms value of the harmonically distorted load currents are lower than their sinusoidal rated currents. Therefore, current harmonics cause the reduction of their useful life. To avoid this problem, cables and transformers should be derated under non-sinusoidal current conditions [4], [9]. Derating factor (maximum permissible current carrying or loading

This work is supported by Turkish Republic Ministry of Science, Industry and Technology and BEST Transformers Co. under the project number of 01008.STZ.2011 - 2 capability) can basically be explained as the ratio between the non-sinusoidal load current's rms value, which causes the rated loss of the equipment (transformer or cable), and the equipment's rated sinusoidal current.

Power factor is conventionally used as an indicator of how effectively are utilized the power transmission and distribution equipment in the power systems [10]. Accordingly, maximization of the classical power factor $(P F)$ is traditionally handled for optimal passive filter design in the literature [11]-[13]. However, [15] clearly interprets that maximization of classical power factor definition, which is calculated by regarding active power and classical apparent power, does not provide the minimum loss condition of a power system having transmission lines with frequencydependent resistances under nonsinusoidal conditions.

This study aims to employ passive filters for effective utilization of the transformers and cables, of which the losses are considerably frequency-dependent, under non-sinusoidal conditions. To achieve this aim, an optimal passive filter design approach is developed to maximize the power factor expression [15], which considers frequency dependent loss of the power system equipment, in non-sinusoidal power systems. The proposed approach can be applied to any kind of passive filters such as single-tuned and high pass filters. In addition, the C-type filter is used for the demonstration of the proposed approach since it provides good filtering performance and reduced fundamental frequency loss when compared to other types of the filters [13].

This paper is organized as follows, on which the present context forms Section I as an introduction to the work. Section II is devoted to the modeling of the studied system. Section III gives the problem formulations of the proposed approach based on the maximization of the power factor defined in [15] and the traditional design approach based on 
maximization of classical power factor. The numerical results obtained with two optimal design approaches are discussed in Section IV. The conclusion is presented in Section V.

\section{Modeling OF The StUdied System}

One-line diagram of the studied system, which is considered in various works [11]-Error! Reference source not found., [16], has a consumer with three-phase linear and non-linear loads, the consumer's transformer \& cable, which carry energy from PCC to the loads and a C-type filter connected to load bus, as shown in Fig. 1. It should be mentioned that some of the linear loads are individually compensated with a basic capacitor.

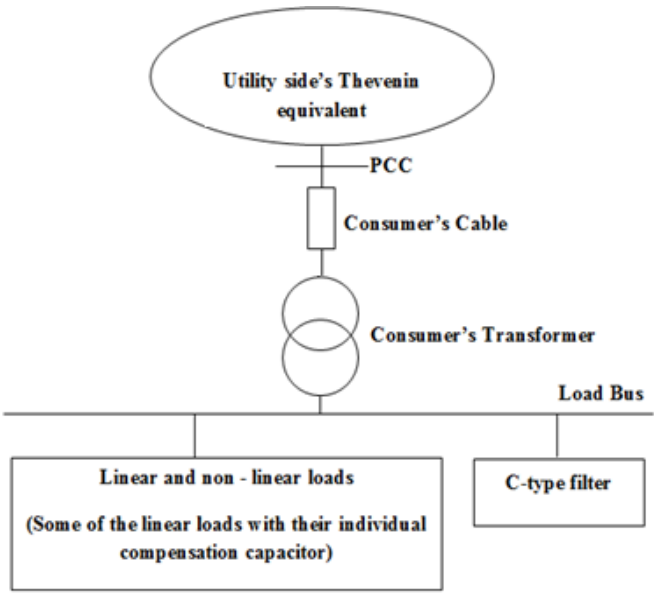

Fig. 1: One-line diagram of the studied system.

To write the current, voltage and power expressions for the system, its single-phase equivalent circuit given in Fig. 2 can be derived since the system is balanced. As shown in this figure, a linear impedance $\left(R_{L}^{\prime}+j h X_{L}^{\prime}\right)$ and a constant current source per harmonic $\left(\underline{I}_{L h}^{\prime}\right)$ denote the linear and non-linear load model parameters [17], which are referred to the primary side of the transformer, where $h$ is the harmonic number. The referred $h$ th harmonic impedance of the individual compensation capacitor, which is preinstalled in the consumer side, is denoted by $-j X_{C i}^{\prime} / h$. Utility side is modelled as Thevenin equivalent voltage source $\left(V_{S h}\right)$ and Thevenin equivalent impedance $\left(\underline{Z}_{S h}\right)$ for each harmonic order. By regarding the skin effect, the $h$ th harmonic resistance $\left(R_{S h}\right)$ of the supply line (Thevenin equivalent) impedance and the $h$ th harmonic resistance $\left(R_{C B h}\right)$ of the cable impedance $\left(\underline{Z}_{C B h}\right)$ can be written as $R_{\mathrm{Sh}}=R_{\mathrm{S}} \sqrt{h}$ and $R_{C B h}=R_{\mathrm{CB}} \sqrt{h}$ where $R_{S}$ and $R_{C B}$ are the fundamental harmonic ac resistances of the supply lines and cables, respectively. In addition, the $h$ th harmonic inductive reactances of the supply lines and cables can be expressed as $X_{S h}=h X_{S}$ and $\quad X_{C B h}=h X_{C B}$, respectively. Note that capacitance of the short overhead lines and all cables can be neglected for the harmonic analysis [17].
With respect to [17], the consumer's transformer is practically modelled using its $h$ th harmonic short-circuit impedance, which is referred to its primary side:

$\underline{Z}_{\mathrm{TRh}}=R_{\mathrm{TRh}}+\mathrm{j} h X_{\mathrm{TR}}$

where $X_{T R}$ is the winding's fundamental harmonic inductive reactance and $R_{T R h}$ denotes the winding's $h$ th harmonic resistance. $R_{T R h}$ consists of two parts such as the winding's dc resistance $\left(R_{T R d c}\right)$ and the winding's equivalent resistance corresponding to the eddy-current loss $\left(R_{T R e c}\right)$ [5], [6]:

$R_{\mathrm{TRh}}=R_{\mathrm{TRdc}}+h^{2} R_{\mathrm{TRec}}$

Fig. 3 shows that single-phase circuit representation of the C-type filter. It consists of the main capacitor $\left(X_{\mathrm{CF} 1}\right)$ in series with a parallel connection of series inductor $\left(X_{\mathrm{LF}}\right)$-capacitor $\left(X_{\mathrm{CF} 2}\right)$ branch and damping resistor $\left(R_{\mathrm{F}}\right)$. Its $h$ th harmonic impedance referred to the primary side of the consumer transformer can be found as;

$$
\begin{aligned}
\underline{Z}_{\mathrm{Fh}}^{\prime} & =a^{2}\left(-\mathrm{j} \frac{X_{\mathrm{CF} 1}}{h}+\frac{\mathrm{j} R_{\mathrm{F}} X_{\mathrm{F}}\left(h^{2}-1\right)}{h R_{\mathrm{F}}+\mathrm{j} X_{\mathrm{F}}\left(h^{2}-1\right)}\right) \\
& =-\mathrm{j} \frac{X_{\mathrm{CF} 1}^{\prime}}{h}+\frac{\mathrm{j} R_{\mathrm{F}}^{\prime} X_{\mathrm{F}}^{\prime}\left(h^{2}-1\right)}{h R_{\mathrm{F}}^{\prime}+\mathrm{j} X_{\mathrm{F}}^{\prime}\left(h^{2}-1\right)}
\end{aligned}
$$

where $a$ is the ratio of primary and secondary voltages of the transformer.



Fig. 3: Single-phase circuit of the C-type filter.

According to the above mentioned modeling issues, for $h$ th harmonic number, the line current, PCC voltage and the load bus voltage, which is referred to the transformer's primary side, can easily be expressed by means of superposition principle:

$$
\begin{aligned}
& \underline{I}_{h}=\frac{\underline{V}_{S h}}{\underline{Z}_{S h}+\underline{Z}_{C B h}+\underline{Z}_{T R h}+\underline{Z}_{F L h}^{\prime}}+\frac{\underline{Z}_{F L h}^{\prime}}{\underline{Z}_{S h}+\underline{Z}_{C B h}+\underline{Z}_{T R h}+\underline{Z}_{F L h}^{\prime}} \underline{I}_{L h}^{\prime} \\
& \underline{V}_{h}=\underline{V}_{S h}-\underline{I}_{h} \underline{Z}_{S h}, \quad \underline{V}_{L h}^{\prime}=\underline{V}_{S h}-\underline{I}_{h}\left(\underline{Z}_{S h}+\underline{Z}_{C B h}+\underline{Z}_{T R h}\right)
\end{aligned}
$$

where $\underline{Z}_{F L h}^{\prime}$ is the parallel equivalent of the load's $h$ th harmonic impedance, the individual compensation capacitor's reactance and the C-type filter's $h$ th harmonic impedance, which are referred to the transformer's primary side. Note that $\underline{Z}_{F L h}^{\prime}$ can be calculated as;

$\underline{Z}_{F L h}^{\prime}=\left(\frac{1}{\underline{Z}_{F h}^{\prime}}+\frac{1}{R_{L}^{\prime}+j h X_{L}^{\prime}}+j \frac{h}{X_{C i}^{\prime}}\right)^{-1}$

Here it should be mentioned that subscript ( $)$ denotes phasor values of the respective voltage, current and impedances. 


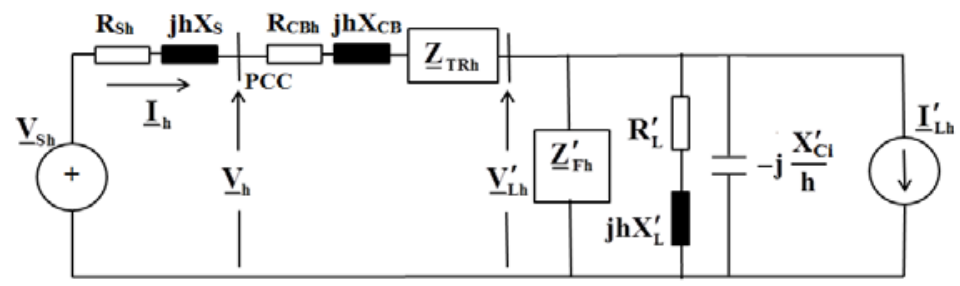

Fig. 2: Single-phase equivalent circuit of the studied system

Thus, by using the voltage and current harmonics found from (4) and (5), the expressions of the THDV and THDI measured at PCC can be written as follows:

$$
T H D V=\frac{\sqrt{\sum_{h \geq 2} V_{h}^{2}}}{V_{1}} \cdot 100, T H D I=\frac{\sqrt{\sum_{h \geq 2} I_{h}^{2}}}{I_{1}} \cdot 100
$$

In addition, the displacement power factor $(D P F)$ and classical power factor $(P F)$ measured at the load bus and the total transmission loss $\left(\Delta P_{\text {Total }}\right)$ can be expressed as

$D P F=\frac{P_{1}}{S_{1}}=\frac{V_{L 1}^{\prime} I_{1} \cos \varphi_{1}}{V_{L 1}^{\prime} I}, P F=\frac{P}{S}=\frac{\sum_{h} V_{L h}^{\prime} I_{h} \cos \varphi_{h}}{\sqrt{\sum_{h}\left(V_{L h}^{\prime}\right)^{2}} \sqrt{\sum_{h} I_{h}^{2}}}$

$\Delta P_{\text {Total }}=3 \sum_{h} I_{h}^{2} R_{\text {Lineh }}$

where $R_{\text {Lineh }}$ is $h$ th harmonic total line resistance $\left(R_{\text {Lineh }}=R_{S h}+R_{C B h}+R_{T R h}\right)$.

On the other hand, with respect to the apparent power definition presented in [15];

$S_{e}=3 V_{e} I_{e}=3 \sqrt{\sum_{h}\left(\frac{R}{R_{\text {Lineh }}} V_{\text {Lh }}^{\prime}\right)^{2}} \sqrt{\sum_{h}\left(\frac{R_{\text {Lineh }}}{R} I_{h}\right)^{2}}$

the power factor at the load bus can be calculated as:

$$
P F_{e}=\frac{P}{S_{e}}=\frac{\sum_{h} V_{L h}^{\prime} I_{h} \cos \varphi_{h}}{\sqrt{\sum_{h}\left(\frac{R}{R_{\text {Lineh }}} V_{L h}^{\prime}\right)^{2}} \sqrt{\sum_{h}\left(\frac{R_{\text {Lineh }}}{R} I_{h}\right)^{2}}}
$$

where $R$ is a reference resistance, which can practically be assumed as any value.

Finally, regarding [2] and [9], for the cables and the transformer employed in the studied system, derating factor values (or the maximum permissible rms current values in percent of the rated current) can respectively be calculated with the expressions given below:

$$
\begin{aligned}
& D F_{C B}(\%)=\left(1+\sum_{h \geq 2}\left(\frac{R_{C B h}}{R_{C B}}\right)\left(\frac{I_{h}}{I_{\text {Base }}}\right)^{2}\right)^{-0.5} \cdot 100 \text { for cables } \\
& D F_{\mathrm{TR}}(\%)=\sqrt{\frac{1+\Delta P_{\mathrm{EC}-\mathrm{R}}(\mathrm{pu})}{1+F_{\mathrm{HL}} \Delta P_{\mathrm{EC}-\mathrm{R}}(\mathrm{pu})}} \cdot 100 \text { for transformer }
\end{aligned}
$$

In (12), $I_{\text {Base }}$ is the base current that should be considered as fundamental harmonic component of the load current, and in (13), $F_{\mathrm{HL}}$ denotes the harmonic loss factor, of which expression can be written as;
$F_{\mathrm{HL}}=\sum_{h} h^{2}\left(\frac{I_{\mathrm{h}}}{I_{1}}\right)^{2} / \sum_{h}\left(\frac{I_{\mathrm{h}}}{I_{1}}\right)^{2}$

The proposed optimal filter design approach based on maximization of $P F_{\mathrm{e}}$ and the traditional optimal filter design approach based on the maximization of $P F$ will be formulated and solved regarding the above mentioned model of the typical industrial power system in the next sections.

\section{PROBLEM Formulations OF THE TRADITIONAL AND The Proposed Optimal Design ApProaches}

The problem formulations of the traditional and the proposed optimal filter design approaches are presented in this section.

\section{A. Traditional design approach}

$P F$ is traditionally used as an indicator of how effectively are utilized the power transmission and distribution equipment in the power systems. Accordingly, maximization of $P F$ has widely been considered as an objective for optimal design of the passive harmonic filters [11]-Error! Reference source not found.. In addition to that, in Error! Reference source not found., the $D P F, T H D V$ and $T H D I$ limitations recommended by IEEE std. 519-1992 [18] are regarded as three constraints of the traditional optimal design approach. Therefore, according to the traditional approach based on the maximization of the classical power factor $(P F)$, optimal design problem of the C-type filter can be formulated as follows:

$$
\begin{aligned}
& \text { Maximize } P F\left(R_{\mathrm{F}}, X_{\mathrm{CF} 1}, X_{\mathrm{F}}\right) \\
& \text { subjected to: } \\
& \operatorname{THDV}\left(R_{\mathrm{F}}, X_{\mathrm{CF} 1}, X_{\mathrm{F}}\right) \leq \operatorname{Max} \mathrm{THDV} \\
& \operatorname{THDI}\left(R_{\mathrm{F}}, X_{\mathrm{CF} 1}, X_{\mathrm{F}}\right) \leq \operatorname{Max} \mathrm{THDI} \\
& 95 \% \leq D P F\left(R_{\mathrm{F}}, X_{\mathrm{CF} 1}, X_{\mathrm{F}}\right) \leq 100 \%
\end{aligned}
$$

where: Equation (15) and Equations (16)-(18) are the objective function and inequality constraints of the problem formulation, respectively. In the inequality constraints, MaxTHDI and MaxTHDV are the maximum allowable THDI and $T H D V$ values, which are stated in IEEE standard 519.

\section{B. Proposed design approach}

As mentioned before, the proposed approach handles maximization of $P F_{e}$ as an objective for the optimal filter design problem. Thus, by regarding the inequality constraints 
given in eq. (16)-(18), the problem formulation of the proposed design approach can be written as;

$$
\text { Maximize } P F_{\mathrm{e}}\left(R_{\mathrm{F}}, X_{\mathrm{CF} 1}, X_{\mathrm{F}}\right)
$$

subjected to:

The inequality constraints given in (16)-(18)

Above detailed optimal filter design problems are solved via FORTRAN feasible sequential quadratic programming (FFSQP) [19]. FFSQP was successfully employed to design the optimal passive filters in several studies [16], Error! Reference source not found., [20]. Readers could refer to [16] and [19] for detailed information about the optimal filter design algorithm based on FFSQP.

\section{NUMERICAL RESUlts}

In this section, the proposed and traditional optimal filter design approaches are numerically evaluated for two cases (Case 1 and 2) of the studied system with the cable types [22], which are detailed in Table I. These cable lines have the same lengths and current carrying capabilities (for sinusoidal current condition) such as $0.1 \mathrm{~km}$ and $640 \mathrm{~A}$, respectively. Fundamental frequency supply voltage and short-circuit power of two simulated cases are predetermined as $6350 \mathrm{~V}$ (line-to-line) and 800 MVA. For the studied system's singlephase equivalent circuit, the impedance parameters of the source and load sides are $R_{S}=0.0038 \Omega, X_{S}=0.0506 \Omega, R_{L}^{\prime}=$ $4.00 \Omega, X_{L}^{\prime}=4.05 \Omega$ and $X_{C i}^{\prime}=100.00 \Omega$. The system consists of a star-star connected consumer transformer with the nameplate ratings such as $7 \mathrm{MVA}$ and $6300 \mathrm{~V} / 400 \mathrm{~V}$. The transformer's winding impedance parameters are $R_{\text {TRdc }}=0.026 \Omega, R_{T R e c}=0.006 \Omega$ and $X_{T R}=0.221 \Omega$. The voltage source harmonics and the current source harmonics referred to the primary side of the transformer are presented in Table II.

TABLE I

PROPERTIES OF CABLE TYPES SIMULATED IN STUDIED SYSTEM

\begin{tabular}{c|c|c|c}
\hline \hline Cases & Cable Type & $\begin{array}{c}\mathrm{R}_{\mathrm{CB}} \\
(\Omega / \mathrm{km})\end{array}$ & $\begin{array}{c}\mathrm{X}_{\mathrm{CB}} \\
(\Omega / \mathrm{km})\end{array}$ \\
\hline \hline \multirow{2}{*}{2} & $\begin{array}{c}6.35 \mathrm{kV}, \text { Trefoil formation, } \\
\text { PVC insulated, }\end{array}$ & 0.098 & 0.1037 \\
\hline \multirow{2}{*}{$\begin{array}{c}\text { Unarmoured, Single core copper wire } \\
240 \mathrm{~mm}^{2} \text { cross sectional area }\end{array}$} & $\begin{array}{c}6.35 \mathrm{kV}, \text { Flat spaced formation, PVC } \\
\text { insulated, Unarmoured, Single core } \\
\text { aluminium wire, } 240 \mathrm{~mm}^{2} \text { cross } \\
\text { sectional area }\end{array}$ & 0.161 & 0.1634 \\
\hline \hline
\end{tabular}

TABLE II

VOLTAGE SOURCE HARMONICS AND CURRENT SOURCE HARMONICS REFERRED TO TRANSFORMER'S PRIMARY SIDE

\begin{tabular}{c|c|c}
\hline \hline$h$ & $\bar{V}_{\mathrm{Sh}}(\mathrm{V})$ & $\bar{I}_{\mathrm{Lh}}^{\prime}(\mathrm{A})$ \\
\hline \hline 5 & $55.00 \angle 0^{\circ}$ & $75.00 \angle-5 \cdot 45^{\circ}$ \\
\hline 7 & $40.00 \angle 0^{\circ}$ & $65.00 \angle-7 \cdot 45^{\circ}$ \\
\hline 11 & $35.00 \angle 0^{\circ}$ & $55.00 \angle-11 \cdot 45^{\circ}$ \\
\hline 13 & $30.00 \angle 0^{\circ}$ & $40.00 \angle-13 \cdot 45^{\circ}$ \\
\hline $17,19,23,25$ & $25.00 \angle 0^{\circ}$ & $15.00 \angle-h \cdot 45^{\circ}$ \\
\hline
\end{tabular}

\begin{tabular}{c|c|c}
\hline \hline $29,31,35,37$ & $12.50 \angle 0^{\circ}$ & $10.00 \angle-h \cdot 45^{\circ}$ \\
\hline $41,43,47,49$ & $7.50 \angle 0^{\circ}$ & $7.50 \angle-h \cdot 45^{\circ}$ \\
\hline \hline
\end{tabular}

For both cases of the uncompensated system, THDV and THDI measured at the PCC, power quantities measured at the load bus, normalized value of the total transmission loss $\left(\triangle P_{\text {TotalN }}\right)$ and loading capabilities $\left(D F_{C B}\right.$ and $\left.D F_{T R}\right)$ of the cable and transformer can be seen in Table III. The normalized total loss is found by regarding its value under the sinusoidal rated current $(640 \mathrm{~A})$. Table III shows that for Case 1 and 2, the active power values $(P)$ drawn by the loads are about $4.5 \mathrm{MW}$. For Case 1, THDV, THDI, PF, $P F_{e}, S$ and $S_{e}$ are $3.812 \%, 25.686 \%, 69.022 \%, 48.783 \%, 6.586 \mathrm{MVA}$ and 9.319 MVA, respectively. On the other hand, for Case 2, THDV $, T H D I, P F, P F_{e}, S$ and $S_{e}$ have the values as $3.824 \%$, $25.840 \%, 68.927 \%, 50.011 \%, 6.574 \mathrm{MVA}$ and $9.060 \mathrm{MVA}$, respectively. Under Case 1 and 2 , the transformer has dramatically reduced loading capabilities $\left(D F_{T R}\right)$ around 64\%. In addition, the cables have reduced current carrying capacities $\left(D F_{C B}\right)$ about $91 \%$. The normalized value of the total transmission loss $\left(\Delta P_{\text {TotalN }}\right)$ has considerably high values as 1.887 and 1.789 in Case 1 and 2 of the uncompensated system, respectively.

TABLE III

POWER QUALITY INDICES, POWER QUANTITIES, LOSSES AND DERATTING FACTORS FOR TWO CASES OF UNCOMPANSATED

\begin{tabular}{c|c|c} 
& SYSTEM & Case 2 \\
\hline \hline & Case 1 & 4.531 \\
\hline$P(\mathrm{MW})$ & 4.546 & 6.574 \\
\hline$S(\mathrm{MVA})$ & 6.586 & 9.060 \\
\hline$S_{e}(\mathrm{MVA})$ & 9.319 & 63.94 \\
\hline$D F_{T R}(\%)$ & 64.106 & 91.014 \\
\hline$D F_{C B}(\%)$ & 91.111 & 3.824 \\
\hline$T H D V(\%)$ & 3.812 & 25.840 \\
\hline$T H D I(\%)$ & 25.686 & 68.927 \\
\hline$P F(\%)$ & 69.022 & 50.011 \\
\hline$P F_{e}(\%)$ & 48.783 & 1.789 \\
\hline$\Delta P_{\text {TotalN }}$ & 1.887 &
\end{tabular}

For both cases of the system, two different optimal filter designs are provided with respect to the proposed and the traditional approaches. The obtained results are presented in Table IV and Table V. It can be seen from these tables that for Case 1 and 2, the traditional approach attains higher $P F$ values as $98.964 \%$ and $98.982 \%$ than the proposed one. Since the proposed approach aims to provide maximum $P F_{e}$ values (89.611\% and $90.625 \%)$, it achieves considerably lower $\Delta P_{\text {TotalN }}$ values as 0.621 and 0.606 than the traditional approach. Both approaches achieve $D P F$ values higher than $99 \%$.

For Case 1, the proposed approach provides higher $D F_{T R}$ value $(88.573 \%)$ than the traditional approach achieving $D F_{T R}$ value as $85.036 \%$. In addition, for Case 2, proposed one gives higher $D F_{T R}$ value $(88.727 \%)$ when compared to the traditional one having $D F_{T R}=85.471 \%$. On the other hand, under the conditions of Case 1 and 2, both approaches result in almost the same $D F_{C B}$ values just above $97 \%$. 
Finally, for Case 1 and 2, the $T H D V$ values achieved by the proposed approach (around 2.67\%) are slightly lower than the $T H D V$ values achieved by the traditional approach (around $2.71 \%$ ). The THDI values observed for the proposed approach (nearly 14.5\%) is larger than the THDI values observed for the traditional one (nearly 13\%) in the simulated cases of the system. At this point, it should be mentioned that both approaches meet the THDV and THDI limits recommended by IEEE std. 519 .

TABLE IV

THE RESULTS OBTAINED WITH THE PROPOSED APPROACH

\begin{tabular}{c|c|c}
\hline \hline & Case 1 & Case 2 \\
\hline \hline$X_{C F I}^{\prime}(\Omega)$ & 7.675 & 7.750 \\
\hline$X_{F}^{\prime}(\Omega)$ & 0.326 & 0.329 \\
\hline$R_{F}^{\prime}(\Omega)$ & 2.886 & 2.914 \\
\hline$D F_{T R}(\%)$ & 88.573 & 88.727 \\
\hline$D F_{C B}(\%)$ & 97.314 & 97.379 \\
\hline$T H D V(\%)$ & 2.674 & 2.675 \\
\hline$T H D I(\%)$ & 14.525 & 14.347 \\
\hline$D P F(\%)$ & 99.240 & 99.359 \\
\hline$P F(\%)$ & 98.190 & 98.325 \\
\hline$P F_{e}(\%)$ & 89.611 & 90.625 \\
\hline$\Delta P_{T o t a l N}$ & 0.621 & 0.606 \\
\hline \hline
\end{tabular}

TABLE V

THE RESULTS OBTAIINED BY THE TRADITIONAL APPROACH

\begin{tabular}{c|c|c}
\hline \hline & Case 1 & Case 2 \\
\hline \hline$X_{C F I}^{\prime}(\Omega)$ & 8.575 & 8.575 \\
\hline$X_{F}^{\prime}(\Omega)$ & 0.389 & 0.389 \\
\hline$R_{F}^{\prime}(\Omega)$ & 5.047 & 4.914 \\
\hline$D F_{T R}(\%)$ & 85.036 & 85.471 \\
\hline$D F_{C B}(\%)$ & 97.514 & 97.569 \\
\hline$T H D V(\%)$ & 2.714 & 2.715 \\
\hline$T H D I(\%)$ & 13.081 & 12.960 \\
\hline$D P F(\%)$ & 99.991 & 99.991 \\
\hline$P F(\%)$ & 98.964 & 98.982 \\
\hline$P F_{e}(\%)$ & 87.635 & 89.008 \\
\hline$\Delta P_{\text {TotalN }}$ & 0.643 & 0.622 \\
\hline \hline
\end{tabular}

\section{CONCLUSION}

An optimal passive filter design approach is developed to maximize the power factor expression, which takes into account frequency-dependent losses of the power transmission and distribution equipment, under nonsinusoidal conditions. Presented simulation results clearly clarify that the proposed approach has a considerable advantage on the reduction of the total transmission losses and the transformer's loading capability under non-sinusoidal conditions when compared to the traditional optimal filter design approach, which aims to maximize classical power factor definition. On the other hand, for the simulated system cases, both approaches lead to almost the same current carrying capability value of the cables.

\section{REFERENCES}

[1] A.P.S. Meliopoulos, M.A.Jr. Martin, "Calculation of secondary cable losses and ampacity in the presence of harmonics," IEEE Trans. on Power Deliv., Vol. 7, No. 2, pp.451-459, Apr. 1992.

[2] A. Hiranandani, "Calculation of cable ampacities including the effects of harmonics", IEEE Trans. on Industry Appl. Mag., Vol. 4, No. 2, pp. 42 - 51, Mar./Apr. 1998.

[3] C. Demoulias, D.P. Labridis, P.S. Dokopoulos, K. Gouramanis, "Ampacity of low-voltage power cables under nonsinusoidal currents", IEEE Trans. on Power Deliv., Vol. 22, No. 1, pp. 584 - 594, Jan. 2007.

[4] C. Demoulias, D.P. Labridis, P. Dokopoulos, K. Gouramanis, "Influence of metallic trays on the ac resistance and ampacity of lowvoltage cables under non-sinusoidal currents", Electric Pow. Syst. Res. Vol. 78, No. 5, pp. 883-896, May 2008.

[5] D. Yildirim, E.F. Fuchs, "Measured transformer derating and comparison with harmonic loss factor (FHL) approach", IEEE Trans. on Power Del., Vol. 15, No. 1, pp. 186-191, Jan. 2000.

[6] E.F. Fuchs, D. Yildirim, W.M. Grady, "Measurement of eddy-current loss coefficient PEC-R, derating of single-phase transformers, and comparison with K-factor approach”, IEEE Trans. on Power Del., Vol. 15, No. 1, pp. 148-154, Jan. 2000.

[7] E.F. Fuchs, D. Lin, J. Martynaitis, "Measurement of three-phase transformer derating and reactive power demand under nonlinear loading conditions", IEEE Trans. on Power Del., Vol. 21, No. 2, pp. 665-672, Apr. 2006.

[8] M.A.S. Masoum, P. S. Moses, A.S. Masoum, "Derating of asymmetric three-phase transformers serving unbalanced nonlinear loads", IEEE Trans. on Power Del., Vol. 23, No.4, pp. 2033-2041, Oct. 2008.

[9] IEEE Recommended Practice for Establishing Transformer Capability When Supplying Nonsinusoidal Load Currents, ANSI/IEEE Standard C.57.110-2008, 2008.

[10] M.E. Balci, A.E. Emanuel, "Apparent power definitions: a comparison study”, IREE Journal, Vol. 6, No. 6, pp. 2713-2722, Nov. 2011.

[11] M.M. Abdel Aziz, E.E. Abou El-Zahab, A.M. Ibrahim and A.F. Zobaa, "LC compensators for power factor correction of nonlinear loads", IEEE Trans. Power Del., Vol. 19, No. 1, pp.331-336, Jan. 2004.

[12] M. M. A Aziz, A. F. Zobaa, A. M. Ibrahim, A. M. A. Monem, "Effect of time variation of system impedance and voltage harmonics on LC compensation for nonlinear loads," IEE Proc. - Electric Power Appl., Vol.153, No.4, p.p. 619-624, Jul. 2006.

[13] M.T. Al-Mathana, A.F. Zobaa and S. H. E. Abdel Aleem, "Economical design of multiple-arm passive harmonic filters for an industrial firm case study," in 15th Int. Conf. Harmonics and Quality of Power, ICHQP'12, Hong Kong, China, Jun. 17-20, 2012, pp. 438-444.

[14] A.B. Nassif, W. Xu and W. Freitas, "An investigation on the selection of filter topologies for passive filter applications", IEEE Trans. on Power Deliv., Vol. 24, No. 3, pp. 1710-1718, Jul. 2009.

[15] S.J. Jeon, "Non-sinusoidal power theory in a power system having transmission lines with frequency-dependent resistances," IET Gener. Trans. \& Distr., Vol. 1, No. 2, pp.331,339, Mar. 2007.

[16] S.H.E. Abdel Aleem, A.F. Zobaa, M. M. Abdel Aziz, "Optimal C-type passive filter based on minimization of the voltage harmonic distortion for nonlinear loads," IEEE Trans. on Ind. Electron., Vol. 59, No. 1, pp. 281-289, Jan. 2012.

[17] S.J. Ranade, W. Xu, "An overview of harmonics modeling and simulation, Tutorial on Harmonics Modeling and Simulation", IEEE Power Eng. Soc. Conf., TP-125-0, pp. 1-7, 1998.

[18] IEEE Recommended Practices and Requirements for Harmonic Control in Electrical Power Systems, IEEE 519, 1992.

[19] J.L. Zhou, A.L. Tits, and C.T. Lawrence, User's guide for FFSQP version 3.7: A FORTRAN code for solving optimization problems, possibly minimax, with general inequality constraints and linear equality constraints, generating feasible iterates, TR-92-107r5, Inst. for Systems Research, University of Maryland, College Park, MD20742, USA, 1997.

[20] A.F. Zobaa, M.M. Abdel-Aziz, and S.H. E. Abdel Aleem, "Comparison of shunt-passive and series-passive filters for DC drive loads," Elec. Pow. Com.\& Syst., vol. 38, no. 3, pp. 275-291, Mar. 2010.

[21] A.F. Zobaa and S.H. E. Abdel Aleem, "A New Approach for Harmonic Distortion Minimization in Power Systems Supplying Nonlinear Loads," IEEE Trans. on Ind. Informatics, in press. 
[22] Caledonian Cables Co., "Medium voltages cables catalogue", accessible online from http://www.caledoniancables.co.uk/DdFls/MV/ Medium\%20Voltage\%20Cables.pdf. 